\title{
Extracorporeal Shock Wave Lithotripsy Treatment for Renal and Ureteral Stones in Duhok City
}

\author{
Shamoo K. AL-Hakary, Suzan M. Haji, Esraa A. Noory, Sonia Z. Issaq \\ Department of Physics, Faculty of Science, University of Zakho, Zakho, Iraq \\ Email: shamookhudaida@yahoo.com
}

Received 28 October 2015; accepted 24 January 2016; published 28 January 2016

Copyright (C) 2016 by authors and Scientific Research Publishing Inc.

This work is licensed under the Creative Commons Attribution International License (CC BY). http://creativecommons.org/licenses/by/4.0/

(c) (); Open Access

\section{Abstract}

The present study reports the results of extracorporeal shock-wave lithotripsy treatment for renal and ureteral stones in Duhok city. The data were collected from the center of breakdown kidney stones in Duhok hospital. There were a total of 40 patients (25 males and 15 females) aged from 20 to 60 years old. The patients harboring ( 23 renal and 17 ureteral) stones of size ranged from 7.5 to $20 \mathrm{~mm}$. Almost stones are of average size $9 \mathrm{~mm}$ and composed of uric acid, calcium and cystine stones. The study has been carried out by taking into consideration the parameters (type, sizes, composition and location of stone as well as region and ages of patients, also power, number of shock wave and sessions). The results show that the stones size increases according to increasing ages of patients (male and female) for uric acid ureter stone and calcium (renal, ureter) stones. Also (renal, ureter) stone size for patients aged from 20 to 30 years old increases from the minimum value for phosphate to maximum value for cystine stones, while for patients aged from $\mathbf{4 0}$ to 60 years old, the minimum size is obtained for calcium oxalate and the maximum size for calcium only. On the other hand, for uric acid stones of average size $9 \mathrm{~mm}$, number of shock wave and sessions as well as the power required to breakdown the stones decrease nearly exponentially according to enhancing patients' ages. At the same time, it's found that for adult patients $(20-30$ years old), number of sessions and the power of shock wave decrease also according to increasing size of calcium and cystine stones. Contrary to that, for the same ages and renal, uretral cysteine stones number of shock wave needed to breakdown large stones will be increased.

\section{Keywords}

Shock wave Lithotripsy, Renal and Ureteral Stones, Stone Size, Adults, Elderly, Patient Ages 


\section{Introduction}

Extracorporeal shock-wave lithotripsy (ESWT) is a method by which stones in the urinary tract are brokendown. The shock-waves produced by the machine are carefully focused on to the area with the use of ultrasound or x-ray imagine. The waves travel through tissues without causing permanent damage and break up the stone into sand like gravel or small pieces. This material will then pass out in your urine over a period of time. It was introduced in the early 1980s and has since become the gold standard for the treatment of urinary stones. It is the most widely performed procedure for stone treatment, treating all size and locations of stones [1]. Extracorporeal shock wave treatment in general is well accepted since it is effective, easy to apply and, usually, without significant side effects. Nevertheless, occasional side effects such as hematoma, petechial bleedings, interactions with cardiac rhythm etc. are reported [2]. The technique works best with stones in the upper ureter between 4 $\mathrm{mm}$ and $2 \mathrm{~cm}$ in diameter [3]. The method is a well-established treatment option for urolithiasis, however, the introduction of new lithotripters appears to have increased the potential problems of shock wave application compared with the first-generation devices [4]. Thirty years after its introduction, extracorporeal shock wave lithotripsy (ESWL) is still the first-line treatment for more than half of all urinary tract stones, but machines and treatment strategies have significantly developed over time. [5] and [6] demonstrate the effects of extracorporeal shock wave lithotripsy on renal blood flow in patients treated for renal/ureteral stones. Experiments carried out by [7] showed that ESWL was a safe, effective, and non invasive treatment option in children. Although it can cause some acute effects in the kidney, there is no long-term effect on the growing kidneys of children. [8] concluded that ESWL remained one of the most commonly utilized treatments for patients with upper urinary tract calculi; stone diameter, location, and number of shock waves were the most important predictors determining stone clearance after ESWL of renal and ureteric calculi. It was found that age and sex had no effect on ESWL success rate also in other studies these factors found play no effect. [9] evaluated the effect of urinary calculi attenuation values from non enhanced computed tomography (stone radiodensity) and stone size in determining the outcome of treatment by ESWL. Flexible ureteroscopy (fURS) has become a more effective and safer treatment for the whole upper urinary tract stones, as well as for large and multiple kidney stones. However, as the stone size becomes larger, the stone-free rate decreases, and the number of operations required increases [10].

The present work investigates the results of application (ESWL) in 40 patients (25 males and 15 females) with renal stones 23 and 17 ureteral stones. The patient's data were collected from the kidney center in Duhok hospital. Research was conducted to study the effect of the parameters (Stones size, compositions, and locations as well as patient's ages, adults and elders) on the outcome number of shock wave, sessions and power of ESWL by taking into consideration the physical behavior and relation among these parameters.

\section{Material and Method}

The study was carried out to collect patient's data from the center of breakdown kidney stones outdoor in Duhok hospital/Kurdistan region/north of Iraq. The work was started from July 2013 to January 2015, and there was a total of 40 patients (25 males and 15 females) harboring renal or ureteral stones, all patient of ages ranged from 20 - 60 years old underwent extracorporeal shock wave lithotripsy (ESWL). The localization of ureteral and renal stones was specified for all patient before treatment through the plan X-ray KUB, as well as stones size which were ranged from $7.5 \mathrm{~mm}$ - $20 \mathrm{~mm}$ were determined by measuring the longest diameter on (kidney, ureter and bladder [KUB] for opaque stone. Plan abdominal film taken routinely to evaluate radio-opacity and stone size [11]. The stones lost on follow up were analyzed in (Dr. Shaker Medical Laboratory) using Renal Stone Analysis. Almost analyzed Duhok stones composed of uric acid, cystine, Calcium with others phosphate and Calcium oxalate. ESWL treatment is performed on the machine Siemens Model Lithostar Multiline, Nixdorf and Modular RLX2- 120.034.06 of the following properties: Operating voltage $104.4 \mathrm{kv}$, Current $4.2 \mathrm{~mA}$ and power ranged from (0.1 - 9) watt, which has a combined ultrasonographic and fluoroscopic display, large energy density in order to obtain optimum focus (without damaging surrounding tissue) and minimal pain that on rare occasions requires for mild sedation-sedation. Number of maximum shock waves used by one ESWL treatment is 5000, while the energy was dependent on stones localization. Our appliance, like most modern appliances used electromagnetic source. The shock waves are transmits to the body through the water, focused by acoustic lens system so that the released energy is reflected on the surface of the stone, see Figure 1. Treatment session consist of 3000 shock waves during time interval (20 - 30) Minuets, all procedures were performed under analgesia. 


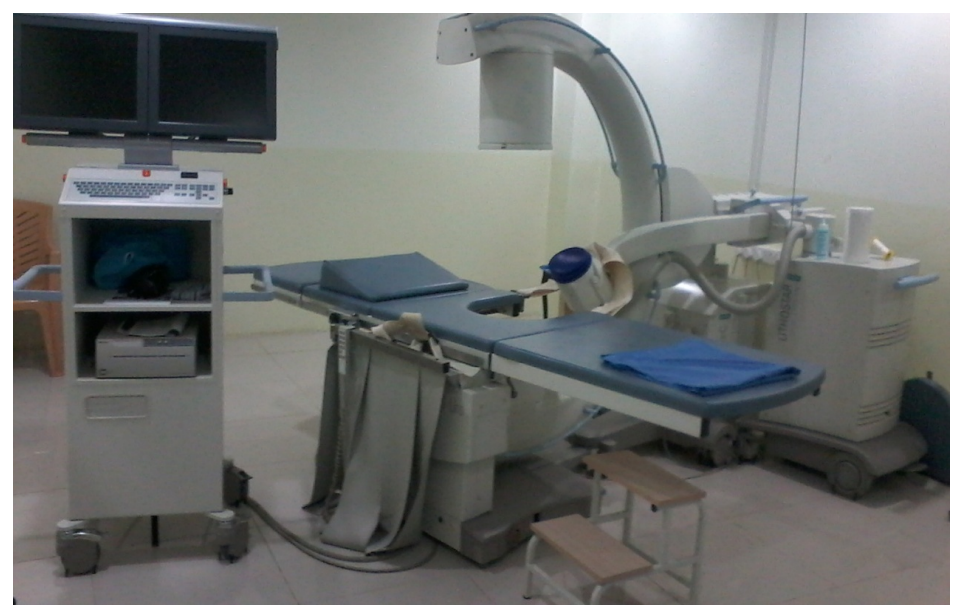

Figure 1. Modern lithotripters for the treatment of kidney and ureteral stones with extracorporeal shock waves in Duhok hospital.

\section{Results and Discussion}

ESWL is very easy and useful method of treatment, and as such a first method of choice in the treatment of kidney stones, less invasive than all other methods, with $80 \%$ - 90\% treatment success. Once we localized place of the calculus, lithotripter breaks the same for thousands of shock waves with an emphasis on regional focal area, which leads to its decomposition into pieces. After treatment, the fragments are removed by urine during the following months [12]. Size of stone, its position and localization as well as ages of patients and sometimes patients' region are prognostic factors that determine the level of disintegration of stone after using ESWL in pediatric patients. According to the analysis of [13], ESWL should be recommended for renal pylon stones up to $24 \mathrm{~mm}$ for the upper or middle calyx to $15 \mathrm{~mm}$, and lower calyx to $11 \mathrm{~mm}$. Although the composition of stone is independent variable that can be useful for predicting the success of ESWL, for most stones is difficult to predict the sensitivity of breaking by the X-ray prior to ESWL. European treatment guidelines advise active ESWL treatment for all stones larger than 6 - $7 \mathrm{~mm}$ [14]. Factors known to alter the extracorporeal lithotripsy outcome are: stone size, location, chemistry, number as well as patient anatomy. Stones larger than $15 \mathrm{~mm}$ and calcium oxalate monohydrate stones usually require several ESWL procedures for clearance. Uric acid, calcium oxalate dehydrates as well as struvite stones are much easier to be disintegrated. ESWL has poor results for stones located in the lower calyx ("stone free" rate of 41\% - 70\%) [15]-[18]. Calculi between $10-20 \mathrm{~mm}$ are still largely treated with ESWL as the first line management. [19]. However; stone composition and location do have an impact on the results of ESWL for stones in this size range and should be carefully considered. As well as patient's ages and sometimes patient's region on the outcome of ESWL. Furthermore attempt has been done to study the physical relations between these parameters after treatment with this technique. Figure 2 represents an increasing relation between uretral uric acid stones size and patient's ages male and female contrary to the previous result obtained by [20], because there is a positive relation between them [21].

During the study attempt was carried out to study the effect of stones size, localization and compositions. While [22], showed that age and sex have no effect on ESWL success rate also in other studies these factors found play no effect.

Also Figure 3 shows nearly a linear increasing of calcium stones size versus patient's ages, male and female.

On the other hand stones size for adult's patients of ages 20 to 30 years as a function of stones compositions is shown in Figure 4. It is clear from figure that the minimum stones size is obtained for phosphate compositions and maximum value for cystine stones due to its hardness. The present result is well agreement with previous work reported by [23], introduced the concept of stone fragility on ESWL, based on the composition of the stone. Cystine and brushite calculi are the most resistant to ESWL, followed by calcium oxalate monohydrate, struvite, calcium oxalate dihydrate, and uric acid stones. Stone composition affects the resistance to fragmentation and the type of fragments produced. Cystine and calcium oxalate monohydrate tend to produce large pieces that are difficult to clear from the collecting system, and they should be treated by ESWL only when the stone burden is small (i.e., $<1.5 \mathrm{~cm}$ ). As well as Figure 5 show similar diagrams for elder patients aged 40 to 60 years old. 


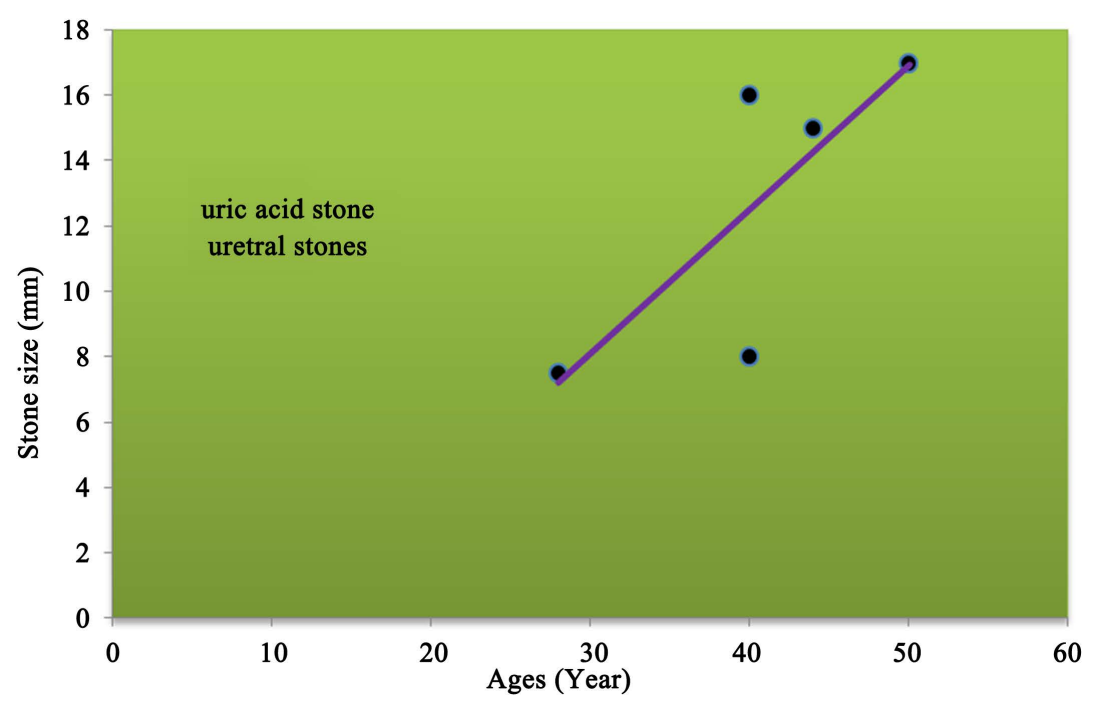

Figure 2. Uric acid stones size versus patient’s ages.

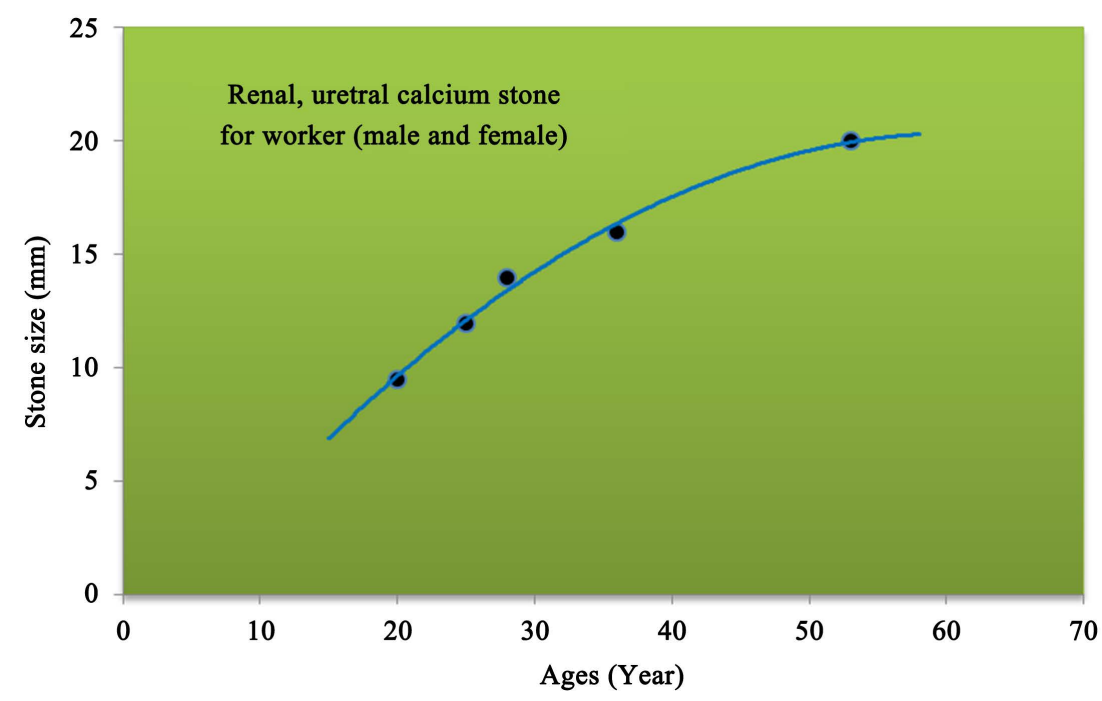

Figure 3. Calcium stones size versus patient's ages.

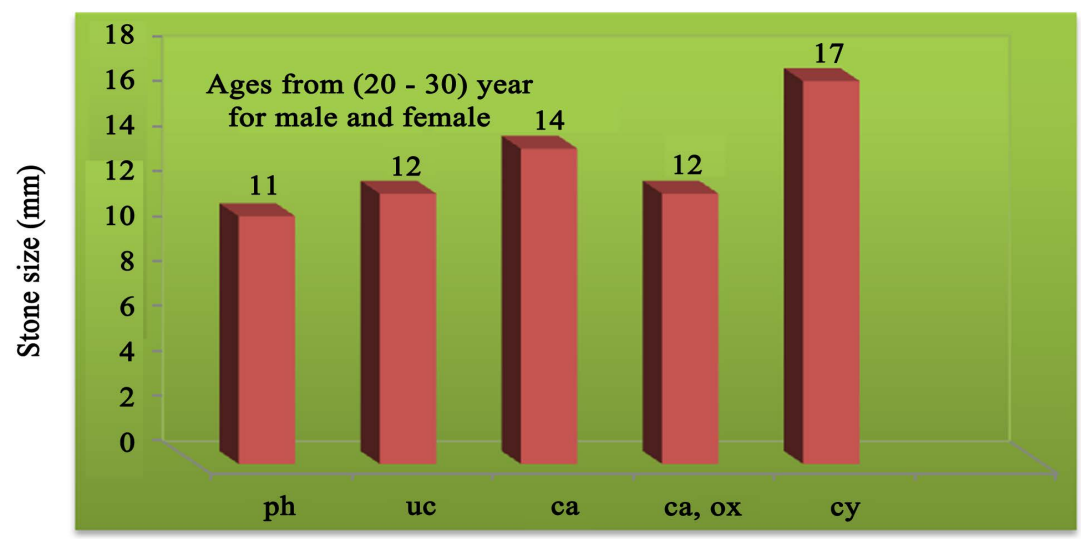

Types of stone

Figure 4. Stones size as a function of stones composition. 


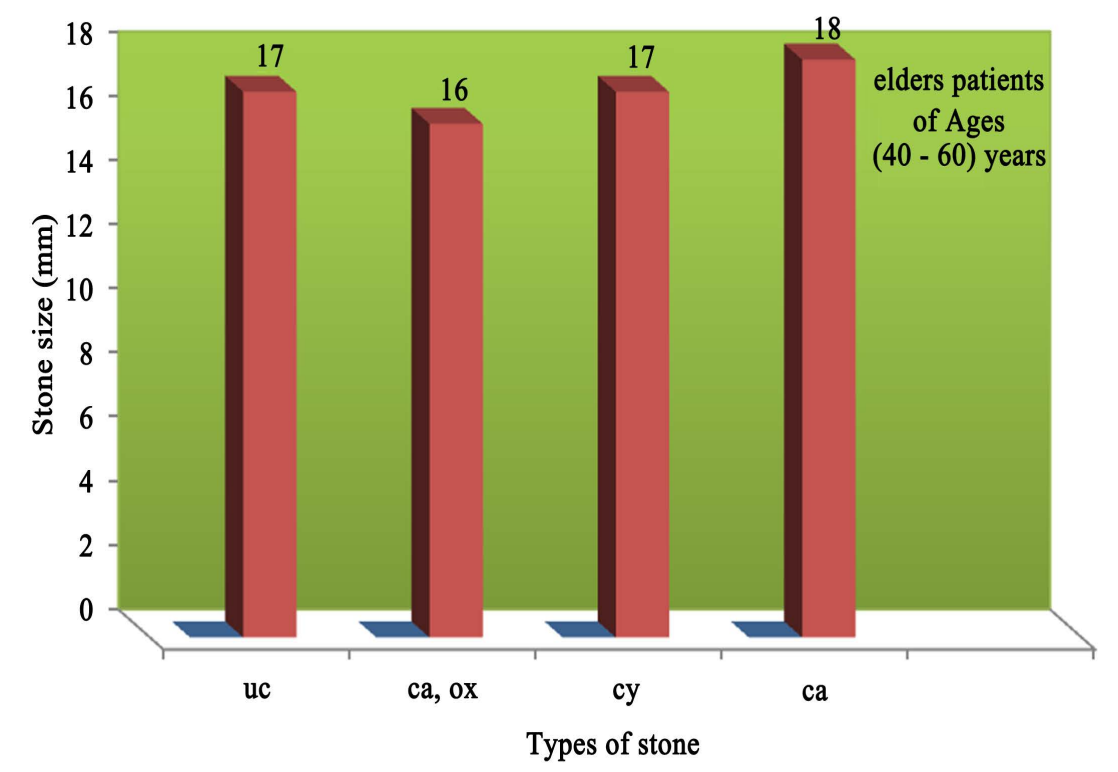

Figure 5. Stones size as a function of stone composition.

However, number of shock wave verus patients' ages for uric acid of average size $9 \mathrm{~mm}$ is shown as a decreasing exponential function in Figure 6. Because elder patients required a poorer treatment with ESWL as conformed by [24], in other words, a negative correlation between patient age and KT. This observation echoed previous discussion that aging would lead to cortical thinning, i.e., an increase in renal scarring. This might also help to explain the observations from previous studies in which older patients had a poorer SWL outcome, because older people are more liable to have a thinner cortex and greater renal scarring [25] and [26].

Number of shock wave session versus patient's ages reveal also negative correlation between them as illustrated in Figure 7 because the stone fragmentation and its removal after ESWL is easier in elders than in adults and starts earlier. Unlike adults due to the small sizes of the body of the elders compared to the adult's body, this probably depends on reaching the stone with less energy loss of the shock waves. Because the distance between the skin and stone in elders is shorter, the shock waves are less absorbed by the surrounding tissue and organs and they reached the stone with less energy loss and their therapeutic effect relatively becomes more. While passing through the body tissue of elders which is thickness is less than the adults, the shock waves have been reported to lose less of their energies [27]. Due to the same reason the shock wave power needed to fragment the elder's stones is less than adult's stones as illustrated in Figure 8. With respect to the number of shock wave variation with stones size, our results for renal and uretral cystine stones, for ages 20 to 30 years indicated positive variation between stones size and number of shock wave (Figure 9).

This is well agreement with the previous research which is predicted a significant positive correlation between the size stone and number of treatments in the total sample (rho $=0.491, p<0.01$ ), respectively, as the stones were larger was needed and a higher number of treatments [28]. On the other hand, number of sessions and power of shock wave as a function of calcium and cysteine stones size respectively for patients' ages from 20 to 30 years are plotted in a nearly decreasing exponential (Figure 10 and Figure 11).

The interesting results are presented by [29], who proved an inverse correlation between the performance of ESWL and size of the stone. As part of their study, the authors demonstrated that the stones of high density, large size and lower localization in the kidney can better administered in a method PCNL (Percutaneous nephrolytopaxy). Later the number of shock wave, shock sessions and its power against stones composition are plotted in Figures 12-14. As illustrated from figures that the phosphate and uric acid need less treatment of ESWL to fragment the stones, while cystine and calcium stones required more treatment of ESWL to fragment due to hardness of a latter stones as indicated by previous research, composition can meaningfully affect the result of ESWL. Uric acid and stone calcium oxalate dihydrath as better fragmentation coefficient compared to calcium oxalate monohydrate and cystine stones [30]. 


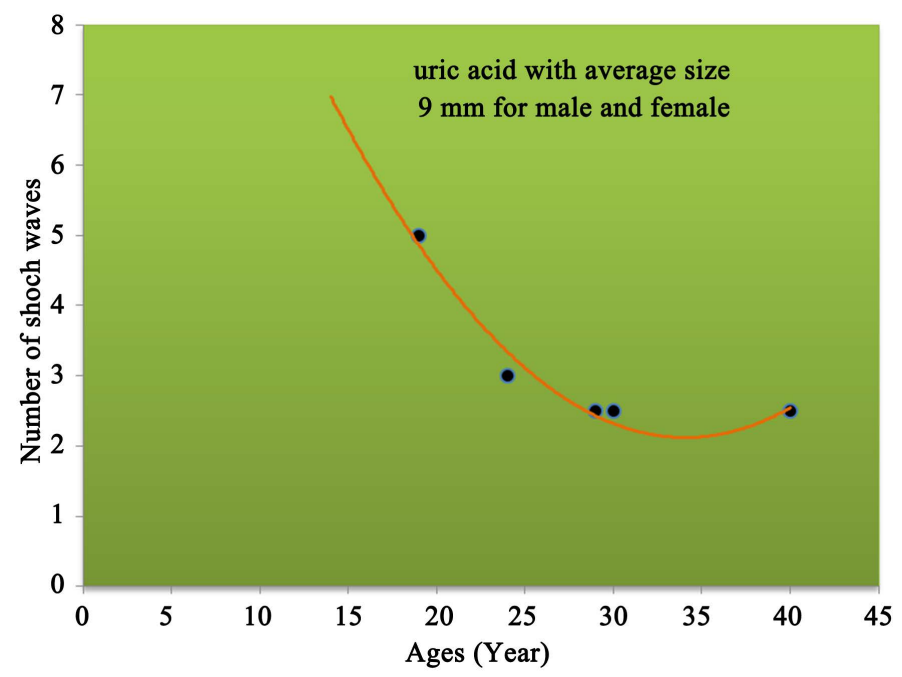

Figure 6. Number of shock wave versus patient's ages.

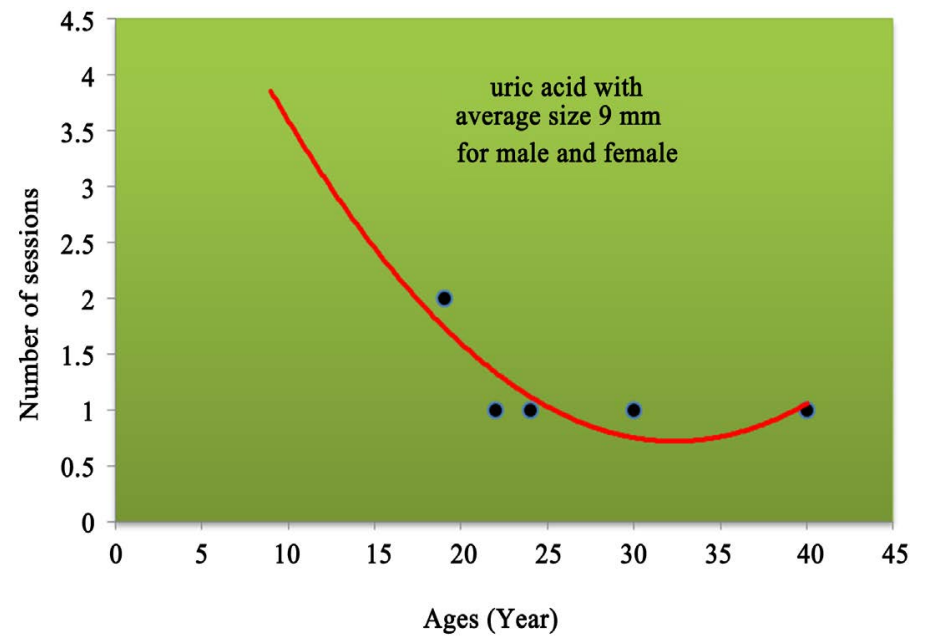

Figure 7. Number of sessions as a function of patient's ages.

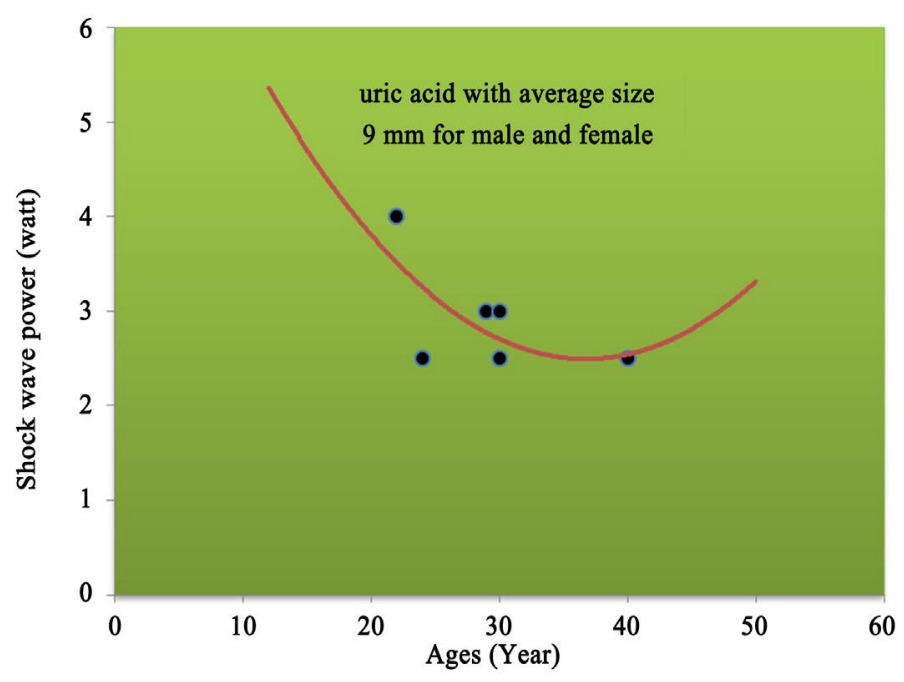

Figure 8. Shock wave power as a function of patient's ages. 


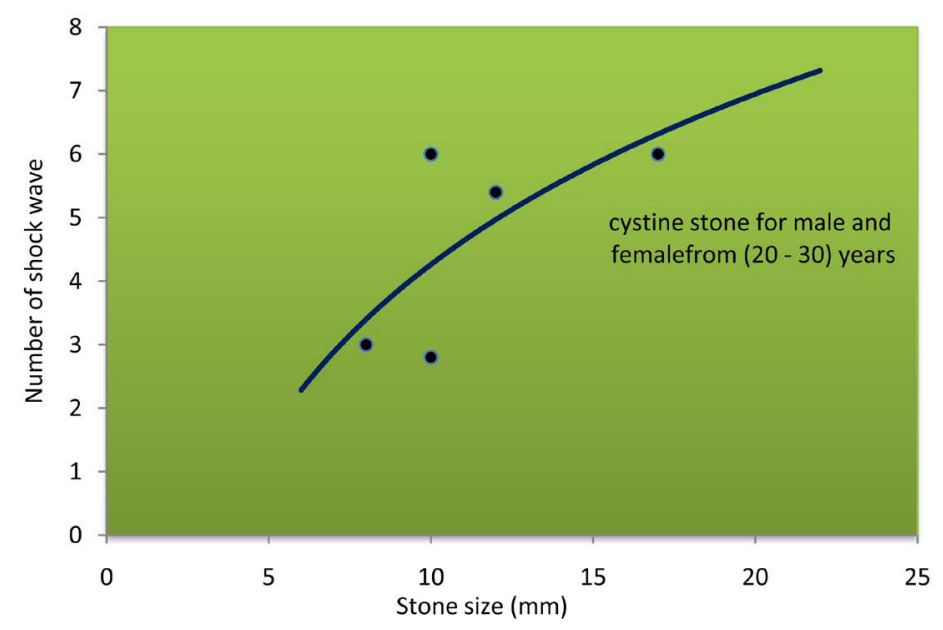

Figure 9. Number of shock wave as a function of stone size.

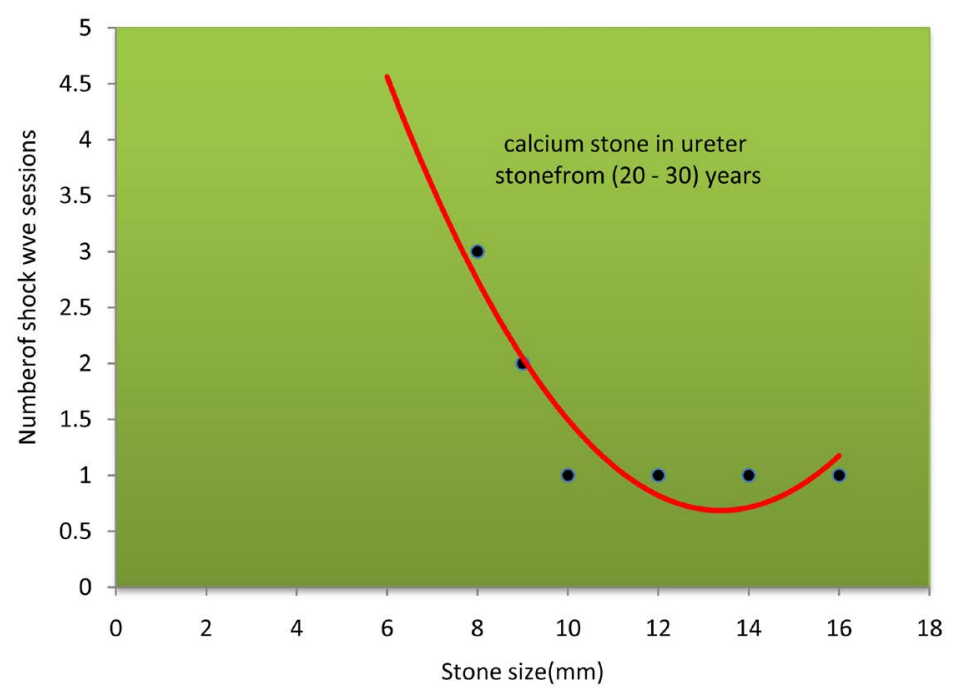

Figure 10. Number of shock wave sessions versus stone size.

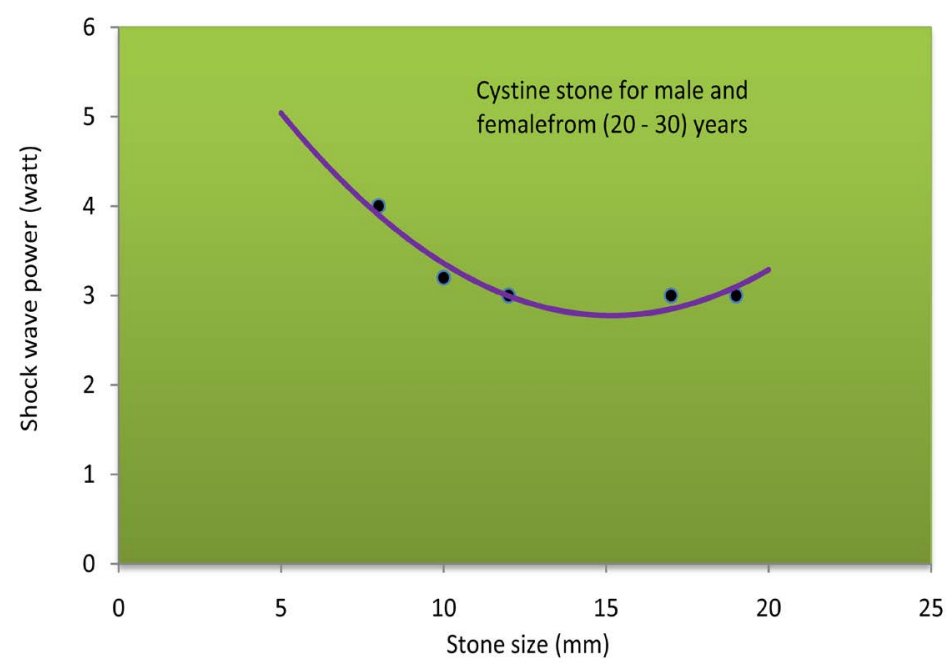

Figure 11. Shock wave power versus stone size. 


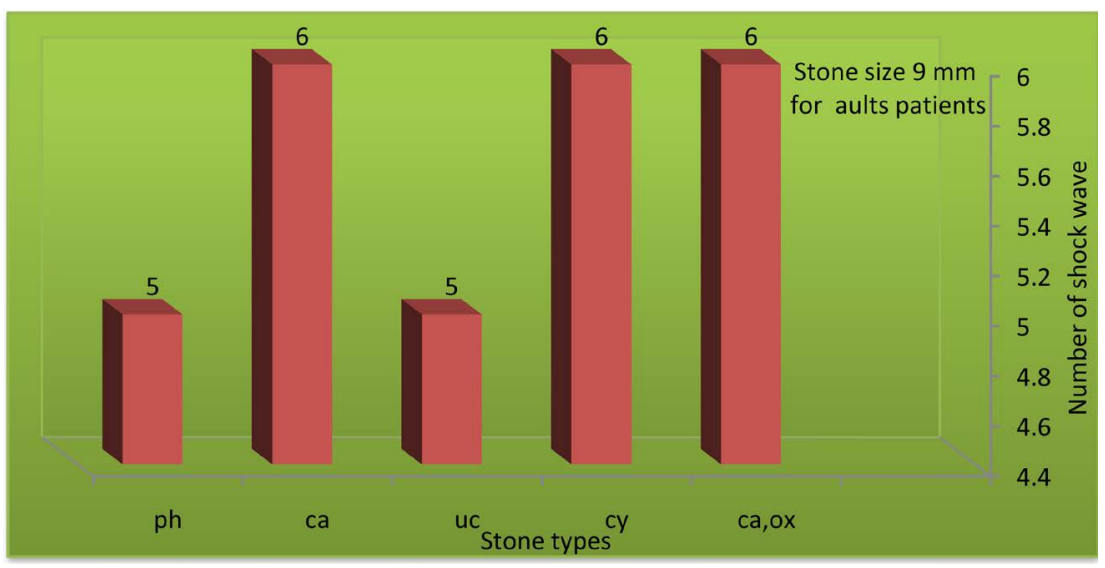

Figure 12. Number of shock wave as a function of stone composition.

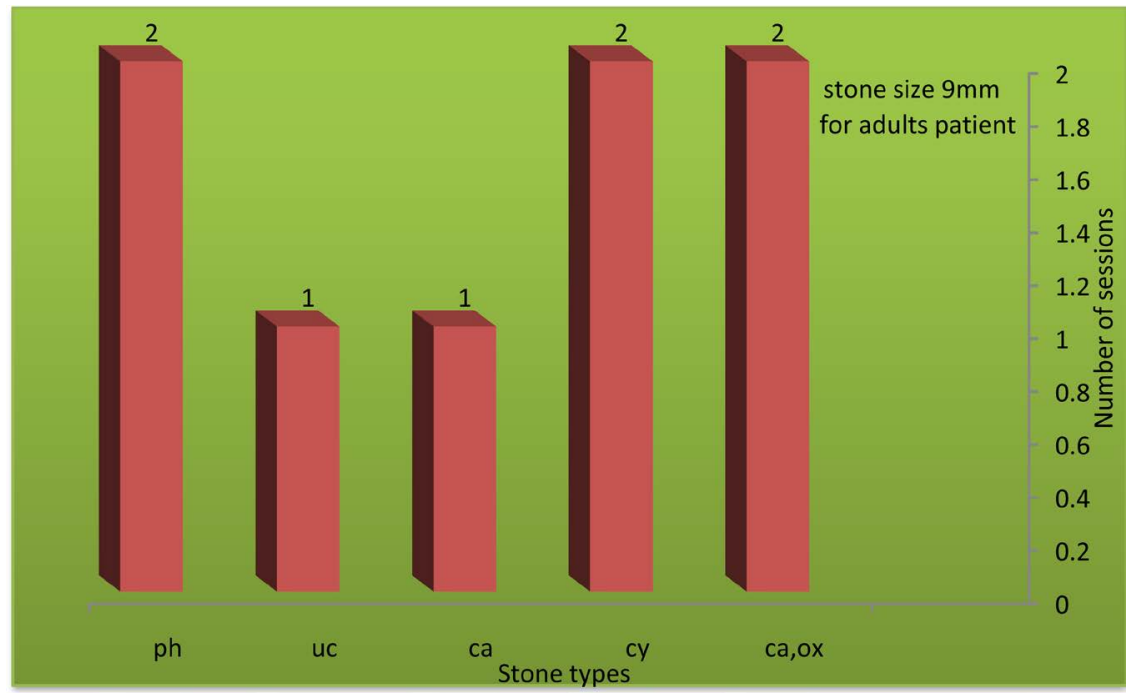

Figure 13. Number of shock wave sessions against stone composition.

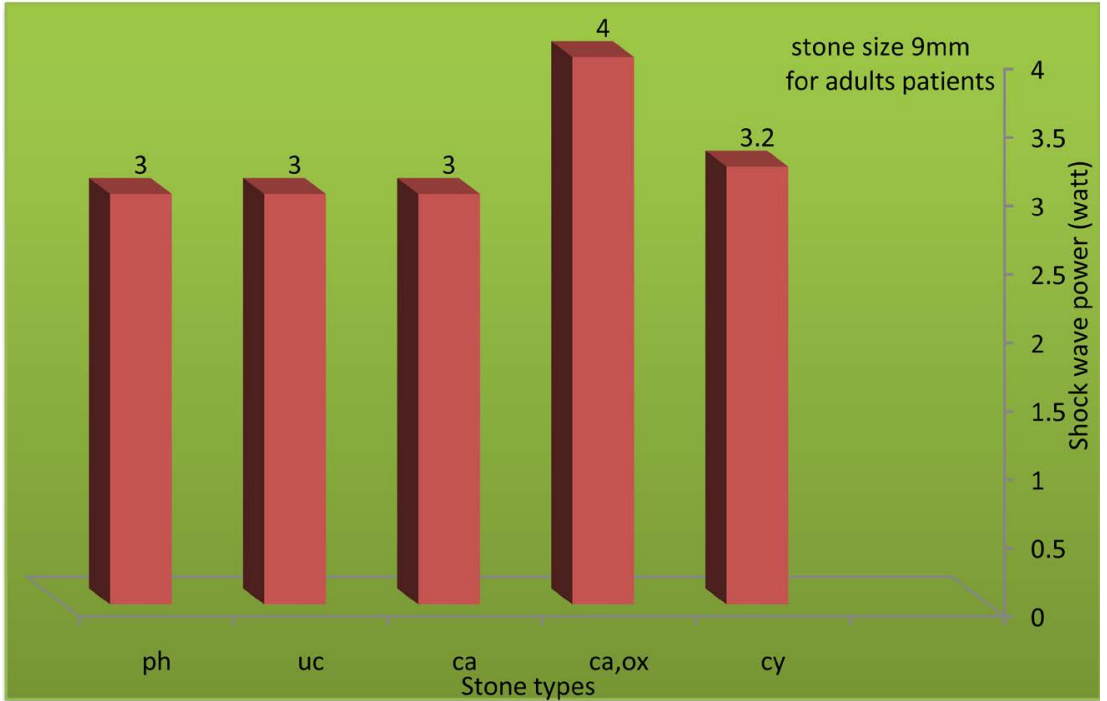

Figure 14. Shock wave power against stones composition. 


\section{Conclusion}

Extracorporeal method can only treat available stones and does not have any effects on their recurrence. ESWL remains one of the most commonly utilized treatments for patients with upper urinary tract calculi; Stone diameter, location, and number of shock waves, are the most important predictors determining stone clearance after ESWL of renal and ureteric calculi. According to our results the efficacy of ESWL is dependent on the size; location and composition of stone as well on the patient's ages. Also sometimes patient's regions are prognostic factors that determine the level of disintegration of stone after using ESWL in pediatric patients. Number of shock wave and its session versus patient's ages reveal negative correlation, because the stones fragmentation and its removal after ESWL are easier in elders than in adults and start earlier. Phosphate and uric acid need less treatment of ESWL to fragment the stones, while cystine and calcium oxalate stones require more treatment of ESWL to fragment due to hardness of the latter stones. Number of sessions and power of shock wave as a function of calcium and cysteine stones size respectively for patient's ages of 20 to 30 years reveal nearly a decreasing exponential due to an inverse correlation between the performance of ESWL and size of the stone.

\section{References}

[1] Urolo, O. and Mohd, A.N. (2006) Extracorporeal Shock-Wave Lithotripsy. Health Technology Assessment Unit, Ministry of Health, Malaysia.

[2] Haecker, A. and Wess, O. (2009) The Role of Focal Size in Extracorporeal Shock Wave Lithotripsy. Research Signpost, 37/661 (2), Fort P.O.Trivandrum.

[3] Wazir, B.G., Iftikhar ul Haq, M., Faheem ul Haq, Nawaz, A., Ikramullah, A.N. and Jamil, M. (2010) Journal of Ayub Medical College Abbottabad, 22, 20-22.

[4] Rassweiler, J.J., Knoll, T., Köhrmann, K.U., McAteer, J.A., Lingeman, J.E., Cleveland, R.O., Bailey, M.R. and Chaussy, C. (2011) European Urology, 59, 784-796.

[5] Bach, C., Karalides, T. and Buchhtz, N. (2012) Arab Journal of Urology, 10, 289-296.

[6] Kurt, S., Tokgöz, Ö., Tokgöz, H. and Voyvoda, N. (2013) Medical Ultrasonography, 15, 273-277. http://dx.doi.org/10.11152/mu.2013.2066.154.sk2

[7] Akin, Y. and Yucel, S. (2014) Research and Reports in Urology, 6, 21-25.

[8] Abid, A.F. (2014) Open Journal of Urology, 4, 26-32. http://dx.doi.org/10.4236/oju.2014.43005

[9] Akbar, A.A., Mahmood, S. and Majid, A. (2015) The Professional Medical Journal, 22, 31-35.

[10] Takazawa, R., Kitayama, S. and Tsujii, T. (2015) World Journal of Nephrology, 4, 111-117

[11] Gallagher, H.J. and Tolley, D.A. (2000) Current Opinion in Urology, 10, 551-555. http://dx.doi.org/10.1097/00042307-200011000-00003

[12] Kovačević-Prstojević, J. (2014) Broj vantjelesnih razbijanja kamenaca uodnosu na veličinu kamenca, njegovu lokalizaciju u urinarnomtraktu, te morfološku strukturu kamenca. Magistarski rad. Medicinski fakultet Univerziteta u Sarajevu. Sarajevo.

[13] El-Nahas, A.R., El-Assmy, A.M., Awad, B.A., Elhalwagy, S.M., Elshal, A.M. and Sheir, K.Z. (2013) International Journal of Urology, 20, 1205-1210. http://dx.doi.org/10.1111/iju.12132

[14] Grasso, M., Hsu, J. and Spaliviero, M. (2008) Extracorporeal Shockwave Lithotripsy. Emedicine by WebMD.

[15] Manu, R. (1998) Litotripsia extracorporeală cu unde de şoc (ESWL). In: Sinescu, I., et al., Eds., Urologie Clinică, Editura Medicală Amaltea, Bucureşti, 162-164.

[16] Tiselius, H.G., Ackermann, D., Alken, P., Buck, C., Conort, P. and Galluci, M. (2001) European Urology, 40, 362-371. http://dx.doi.org/10.1159/000049803

[17] Yang, H.S., Park, K.S. and Min, B.K. (1993) Korean Journal of Urology, 34, 109-115.

[18] Argyropoulus, A.N. and Tolley, D.A. (2007) European Urology, 52, 344-350. http://dx.doi.org/10.1016/j.eururo.2007.04.066

[19] Clayman, R.V., McDougall, E.M. and Nakada, S.Y. (1998) Percutaneous Therapeutic Procedures. In: Walsh, P.C., Retik, A.B., Vaughan, E.D. and Wein, A.J., Eds., Campbell's Urology, WB Saunders, Philadelphia, 2809-2864.

[20] Al-Hakary, S.K. (2015) Journal of Modern Physics, 6, 869-877.

[21] Lin, C.-C., Hsu, Y.-S. and Chen, K.-K. (2008) Journal of the Chinese Medical Association, 71, 496-501.

[22] El-Assmy, A., El-Nahas, A.R. and Mohamed, E. (2006) The Scientific World Journal, 6, 2388-2390. http://dx.doi.org/10.1100/tsw.2006.370 
[23] Dretler, S.P. and Polykoff, G. (1996) Journal of Urology, 155, 828-833. http://dx.doi.org/10.1016/S0022-5347(01)66319-5

[24] Ng, C.F., Luke, S., Chiu, P.K., Teoh, J.Y., Wong, K.T. and Hou, S.S. (2015) Korean Journal of Urology, 56, $379-385$.

[25] Ikegaya, H., Kato, A., Kumano, S. and Tominaga, T. (2005) BJU International, 96, 1145. http://dx.doi.org/10.1111/j.1464-410X.2005.05924_2.X

[26] Ng, C.F., Wong, A. and Tolley, D. (2007) BJU International, 100, 392-395. http://dx.doi.org/10.1111/j.1464-410X.2007.06909.x

[27] Longo, J.A. and Netto, N.R. (1995) Urology, 46, 550-552. http://dx.doi.org/10.1016/S0090-4295(99)80271-4

[28] Junuzovic, D., Prstojevic, J.K., Hasanbegovic, M. and Lepara, Z. (2014) Acta Informatica Medica, 22, 309-314. http://dx.doi.org/10.5455/aim.2014.22.309-314

[29] Tarawneh, E., Awad, Z., Hani, A., Haroun, A.A., Hadidy, A., Mahafza, W. and Samarah, O. (2010) Saudi Journal of Kidney Diseases and Transplantation, 21, 660-665.

[30] Maltaga, B.R. and Lingerman, J.E. (2011) Surgical Management of Upper Urinary Tract Calculi. In: Wein, A.J., et al., Eds., Cambell-Walsh Urology, 10th Edition, Elsevier Science, Toronto, 1357-1410. 